\title{
BMJ Open Finnish HIV Quality of Care Register (FINHIV)
}

\author{
Mikaela Mutru (D) , ${ }^{1,2}$ Sanna Isosomppi, ${ }^{3}$ Inka Aho, ${ }^{1,2}$ Kirsi Liitsola, ${ }^{3}$ \\ Henrikki Brummer-Korvenkontio, ${ }^{3}$ Jukka Ollgren, ${ }^{3}$ Oskari Luomala, ${ }^{3}$ Pia Kivelä ${ }^{1,2}$
}

To cite: Mutru M, Isosomppi S, Aho I, et al. Finnish HIV Quality of Care Register (FINHIV). BMJ Open 2022;12:e053287. doi:10.1136/ bmjopen-2021-053287

- Prepublication history for this paper is available online. To view these files, please visit the journal online (http://dx.doi org/10.1136/bmjopen-2021053287).

Received 10 May 2021

Accepted 30 December 2021

Check for updates

(c) Author(s) (or their employer(s)) 2022. Re-use permitted under CC BY-NC. No commercial re-use. See rights and permissions. Published by BMJ.

${ }^{1}$ Faculty of Medicine, University of Helsinki, Helsinki, Finland ${ }^{2}$ Department of Infectious Diseases, Helsinki University Central Hospital Inflammation Center, Helsinki, Finland

${ }^{3}$ Department of Health Security, Finnish Institute for Health and Welfare, Helsinki, Finland

Correspondence to

Dr Mikaela Mutru;

mikaela.mutru@helsinki.fi

\section{ABSTRACT}

Purpose The Finnish HIV Quality of Care Register (FINHIV) was created to: (1) estimate the number of people living with HIV (PLWH) in Finland, (2) evaluate the national level of antiretroviral medication use and viral suppression, (3) examine the change in the HIV epidemic in Finland to pinpoint issues to address and (4) enable evaluation of the health of the PLWH by combining the FINHIV data with other national healthcare data.

Participants The FINHIV includes all people diagnosed or being treated for HIV infection in Finland since 1984. The register was formed in 2020 by combining data from the National Infectious Diseases Register (information from time of diagnosis, data from 1984) and from the 21 HIV Clinics that treat HIV-positive patients in Finland (earliest data from 1998). The register population forms a nationwide, open cohort with yearly updates; currently it consists of 4218 PLWH (including 718 deceased) with HIV diagnosed or treated in Finland 1984-2019. Current rate of new cases is 150 cases/year.

Findings to date From the FINHIV data, we can confirm that Finland has reached the Joint United Nations Programme for HIV/AIDS (UNAIDS) 90-90-90 targets set for 2020, and that the proportion of virally suppressed is constant between all 21 HIV Clinics in Finland, despite their varying size. Linkage to care is estimated at $94.3 \%$ of those diagnosed. In contrast to the treatment results, more than half of the PLWH have been diagnosed at a late stage, and the proportion has increased since 2000.

Future plans Combinations of FINHIV data with other national healthcare register data in Finland will provide further information on other aspects of the health of the PLWH in a high-resource setting (eg, comorbidities, sexual health and use of healthcare resources). Additionally, implementation of patient-reported experience and outcome measures within the FINHIV is ongoing.

\section{INTRODUCTION}

The Finnish HIV Quality of Care Register (FINHIV) is a national register that was created in 2020 to provide data on the epidemiology and treatment results of HIV infection in Finland; the register population includes all people diagnosed or treated for HIV infection in the country since 1984 . The register combines information collected by mandatory reporting at the time of HIV diagnosis to treatment results recorded at regular HIV Clinic follow-up visits. This

\section{Strengths and limitations of this study}

- The Finnish HIV Quality of Care Register (FINHIV) population forms an open cohort of all people diagnosed or treated for HIV infection in Finland since 1984.

- Follow-up data including laboratory results and use of antiretroviral medication are yearly updated.

- Ninety per cent of the FINHIV population have a valid personal identity code that will enable combining the register data with other national registers to study other aspects of the health of the people living with HIV (PLWH) in a high-resource setting.

- A limitation of the study is that while information recorded at the time of HIV diagnosis is available for the whole population, the follow-up data on HIV treatment consist of routinely collected data from HIV Clinics and is largely missing before 1998.

- Incomplete immigration and emigration data lead to a margin of error in the estimate of the number of PLWH currently living in the country without attending follow-up.

article describes the formation, information content, first results and future research plans for the FINHIV cohort.

The FINHIV allows an accurate assessment of the number of people diagnosed with HIV in Finland from the start of the HIV epidemic. From the register data, we can evaluate the antiretroviral treatment (ART) use, treatment outcome, linkage to care and estimate the diagnostic delay of the current patient population and follow Finland's progress towards the Joint United Nations Programme on HIV/AIDS (UNAIDS) 90-90-90 for 2020 and 95-95-95 for 2030 global treatment targets for HIV ${ }^{1-3}$ We can also compare these results between hospitals and regions in Finland. Furthermore, to obtain a more comprehensive view on the quality of care of the people living with HIV (PLWH) in Finland, methods for implementing patient-reported experience and outcome measures into the FINHIV are currently being developed.

Every Finnish citizen or resident is given a unique 10-digit personal identity code (PIC) 
that all healthcare providers nationwide use to identify an individual. We used the PIC to compile the FINHIV data from its sources, but it is also used in other official registers. Thus, in addition to examining the variables directly related to HIV treatment that are collected in the FINHIV, it is possible to accurately combine the information with other national registers or medical records. In this way, additional data regarding, for example, comorbidities, medication unrelated to HIV infection or use of healthcare resources can be obtained.

\section{COHORT DESCRIPTION}

The FINHIV is maintained in the Finnish Institute for Health and Welfare (THL) in Helsinki, Finland. It was one of the pilot registers included in THL's Quality of Care Register Project that aimed to develop several national healthcare registers focusing on different diseases, disease groups or interventions. ${ }^{4}$ The FINHIV was developed as a co-operative effort of THL and the physicians working in the Finnish HIV Clinics, with representatives of a patient organisation (Positiiviset-HivFinland) forming a part of the working group. The data collection and combination of data to form the FINHIV were approved by THL (THL/1572/6.02.00/2019).

\section{Data sources}

THL maintains the National Infectious Diseases Register (NIDR), which was established as a nationwide register in 1995. The NIDR includes the data from a previous HIV register used in 1984-1994 and some retrospectively added information from 1980 to 1983 (J. Löflund (THL), personal comm.). Reporting an HIV diagnosis to the NIDR is mandatory by Finnish legislation. ${ }^{5}$ Laboratories report to the register the individuals' first positive HIV test results (antibody/antigen/viral load) and physicians' reports supply additional information (including date of the diagnosis, mode of transmission, HIV viral load and CD4+ cell count at diagnosis). The register information is further supplemented by data from the Population Information System (date and country of birth, date of death).

In Finland, the follow-up of PLWH is organised in the HIV Clinics of 21 hospitals, and the clinics record information relevant to the treatment of HIV (eg, laboratory results, medication and relevant coinfections such as hepatitis C). Of these clinics, the HIV Clinics of all five tertiary care hospitals and six secondary care hospitals currently use a local register programme (InfCare HIV, Health Solutions SE and BCB Medical, Finland), and the rest of the clinics store information only on electronic medical records.

\section{Eligibility}

The FINHIV consists of all people diagnosed with or being treated for HIV infection in Finland since 1 January 1984, as listed in either the NIDR or the HIV Clinics' records (local register or medical records). Diagnosis of HIV relied on clinical characteristics for the first diagnosed patients in 1983-84 but has been based on an antibody test since 1985 .

\section{Register formation}

The FINHIV was formed by collecting data from all HIV Clinics and combining it with the NIDR. The data from the HIV Clinics are transferred to THL either via data transfer by the local register provider or as a datasheet file that has been manually filled from hospital medical records. First collection and combination of full data from all sources took place from February 2020 to September 2020. This initial population data were further supplemented in fall 2020 with information from the Population Information System and the Finnish Immigration Service (immigration and emigration dates, if available). After initial formation, the FINHIV will be updated yearly from its sources to include new cases from the previous year as well as updated information on the cases that are already included.

When combining the data to form the FINHIV, the PIC was used as an identifying factor. A valid PIC was missing for 545 of the cases listed in the sources, and these cases were examined individually. The missing information included a few apparent typing errors but was mostly due to entries of foreign-born individuals: either short-term visitors or immigrants who had not yet received permanent PICs. In 124 of these cases, we could reliably identify a duplicate report of the same person under another PIC based on other available information (name, date of birth, country of birth, date of HIV diagnosis). The rest of the cases with an invalid or missing PIC $(n=421)$ were included in the FINHIV database, but they can only be used for analyses within the FINHIV; these cases cannot be reliably compiled with data from other sources that use the PIC as an identifier (eg, other national registers).

The formation of the register with current cohort (1984-2019) information is depicted in figure 1.

\section{Information content}

For the clinics that use a datasheet file, the current minimum requirement of information is six parameters (PIC, start of follow-up date, latest CD4+ cell count and its date, latest HIV viral load (copies/mL) and its date and latest ART medication (name, starting date and ending date)). A larger collection of parameters (up to 40 variables including laboratory results) is automatically included in the transfer from the HIV Clinics that use a local register. Data sources and collected information are depicted in table 1 .

The clinics that use the local register programme and provide the larger data set are responsible for the treatment of $88 \%$ of those who attended follow-up in 2019 and provide information for $73 \%$ of the whole FINHIV population. The HIV Clinic of Helsinki University Hospital, responsible for the treatment of $62 \%$ of those currently in follow-up, was the first in Finland to start using the current local register programme in 2014, and their local register programme includes clinical data from 1998. The other 


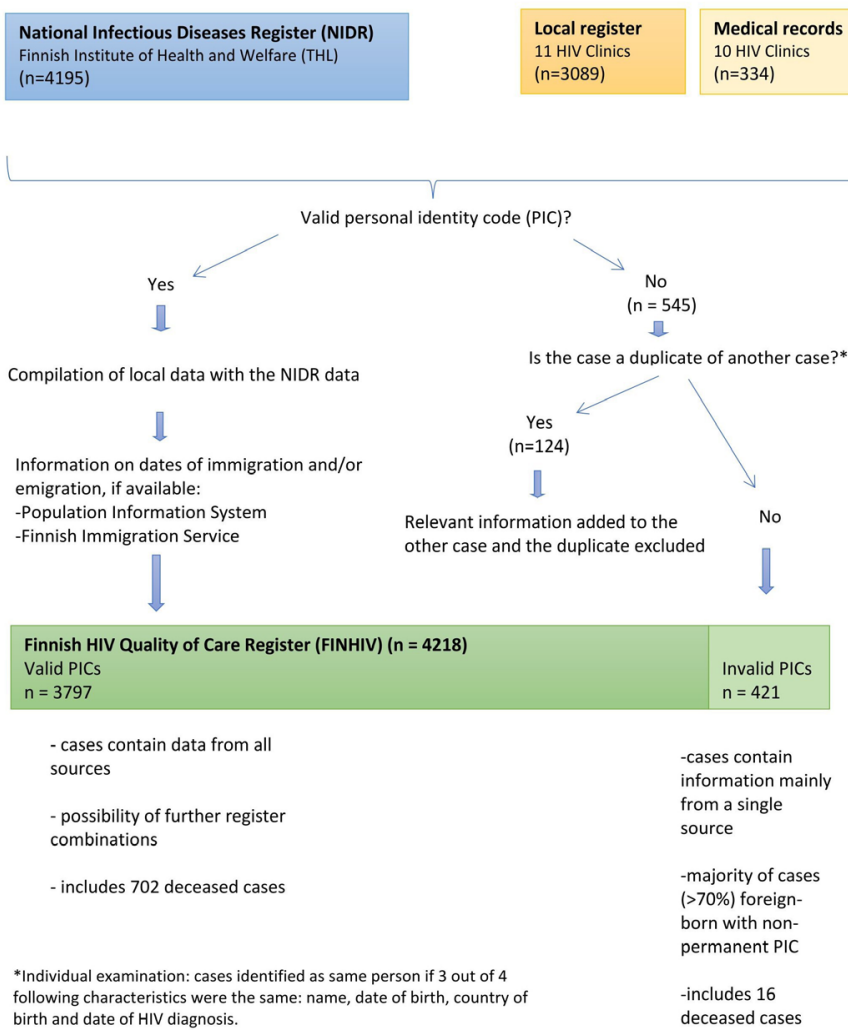

Figure 1 Formation of the current (1984-2019) Finnish HIV Quality of Care Register (FINHIV) cohort.

HIV Clinics took up the local register programme later (2016-2019), with retrospective information filled into a varying degree. This means that the data on medication and laboratory results are largely missing before 1998, and from then onwards the included data proportion increases over time. As the data collection took place in 2020, all patients who were treated at Finnish HIV Clinics in 2019 are included the FINHIV data, and current ART use and latest HIV-related laboratory results are available for all of them.

The register population is followed according to national guidelines at the HIV Clinics, the current practice being two times a year.

\section{Patient and public involvement}

Representatives of a patient organisation (PositiivisetHivFinland) were a part of the working group that planned and executed the formation of the FINHIV. The use of the data including data protection issues was discussed with the patient organisation. Information on the register was made available to the public on a website, in newsletters published by the patient organisation and by THL and in a public event on World AIDS Day 2019.

\section{Cohort characteristics}

The register population currently consists of 4218 people, including 718 deceased cases. At the end of 2019, a total of 2763 people were in follow-up; they had their HIV viral load measured in 2019 (ie, attended follow-up at an HIV
Clinic) and had not died or emigrated by the end of the year. The characteristics of the current FINHIV population are described in table 2.

We estimated non-linkage to care by examining the cases who have not died or known to have emigrated but were not in follow-up at the end of $2019(n=612)$. The emigration data in the Population Information System are incomplete as it relies on reporting by the emigrated individuals ${ }^{6}$; only 125 cases are listed as emigrated in the FINHIV sources. Additionally, immigrants are often diagnosed or receive ART both before and after receiving their valid PIC, resulting in possible duplicate entries in the data. For these reasons, we excluded from those considered not linked to care 444 cases who are likely to either have left the country or to receive ART and be registered in the FINHIV under another PIC. The reasons for exclusion were (1) HIV diagnosis before 2010 and no laboratory measurements or indications of ART after $2009(n=380)$, or (2) HIV diagnosis before 2015, no laboratory measurements or indications of ART after 2014 and the PIC is invalid (suggesting recent immigrant; $\mathrm{n}=64$ ). Thus, we estimated that only the remaining 168 cases were truly not linked to care at the end of 2019, resulting in an estimated total of 2931 people with HIV diagnosis living in Finland at the end of 2019, with $94.3 \%$ of them linked to care. Changing the criteria of exclusion from not linked to care only to reason 1 (ie, no record of diagnosis, treatment or follow-up in the last 10 years) or to modifying reason 2 to also exclude those with a valid PIC (ie, excluding all with no record of diagnosis, treatment or follow-up in the last 5 years) would result in 232 or 125 cases not linked to care, respectively. These would lead to the percentage of linked to care to be $92.3 \%$ or $95.7 \%$, respectively.

\section{FINDINGS TO DATE}

To evaluate the standard of care by the 90-90-90 targets, we used the incidence method of the ECDC HIV Modelling Tool to estimate the proportion of the PLWH living in Finland that are undiagnosed. ${ }^{7}$ The method is a multistate back-calculation method that uses the number of annual new HIV diagnoses, the CD4+ cell count within 90 days of diagnosis and the annual number of AIDS cases (both all cases and the number of those concurrent with HIV diagnosis) for the estimation, and the estimate is adjusted for the number of deaths. ${ }^{8}$ Migration was not adjusted for in the estimation. A 95\% CI was obtained with bootstrapping (100 iterations). Default parameters were used, but sensitivity tests of the analysis with different parameter values did not significantly change the results. The resulting estimate was that, in 2019, 6.6\% (95\% CI $5.4 \%$ to $10.3 \%)$ of the PLWH in Finland were undiagnosed, and consequently that $93.4 \%$ of the PLWH living in Finland in 2019 were diagnosed.

Of those diagnosed and presumed to be living in Finland (n=2931; 2763 attending follow-up in 2019 and 168 not linked to care), 2707 individuals (92.4\%; 
Table 1 Information sources for Finnish HIV Quality of Care Register

\section{Source of information (maintainer)}

Collected piece of information

National Infectious
Diseases Register
(THL*)

Local register or
medical records
(HIV Clinics)

Population Information System Immigration $\left(\mathrm{THL}^{*}\right)$

$\begin{array}{ll}\text { Personal identity code } & x \\ \text { Sex } & x\end{array}$

Date of birth

Date of death

Country of birth

Date of immigration

Date of emigration

Mode of transmission

$\mathrm{x} \quad \mathrm{x} \S$

$x \quad x$

Country of transmission

Date of HIV diagnosis

Date of AIDS diagnosis

AIDS-defining diagnosis

$\mathrm{x}-\mathrm{x}$

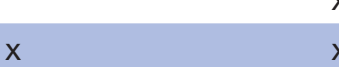

$\mathrm{X}$

Hepatitis C antibodies (positive/negative)

Hepatitis B S-antigen (positive/negative)

CD4 + cell count at diagnosis (cells/ $\mu \mathrm{L}$ )

HIV viral load (copies/mL) at diagnosis

Treating HIV Clinic

Start of follow-up date

End of follow-up date

CD4 +cell count during follow-up (cells/

$\mu \mathrm{L})$, with dates

\begin{tabular}{ll} 
HIV viral load during follow-up (copies/ & $x \S$ \\
mL), with dates & \\
\hline HLAB5701ๆ & $x$ \\
\hline Date of drug resistance test & $x$ \\
\hline Antiretroviral medication & $x \S$ \\
\hline Starting date of each medication & $x \S$ \\
\hline Ending date of each medication & $x \S$ \\
\hline Blood pressure & $x$ \\
\hline Height & $x$ \\
\hline Weight & $x$ \\
\hline Smoking (yes/no, has quit/no, never) & $x$ \\
\hline Additional laboratory test results* & $x$ \\
\hline
\end{tabular}

*Finnish Institute for Health and Welfare.

†Digital and Population Data Services Agency.

†For cases born abroad, dates of immigration and emigration (if available) were collected as a one-time data transfer in August 2020 for the initial register formation; possibly included in further updates.

§Minimum requirements of information from HIV Clinics. For CD4 +cell count, HIV viral load and antiretroviral medication, latest dates were the minimum requirement.

IPresence of major histocompability complex class I allele HLAB5071 (abacavir hypersensitivity).

${ }^{\star *}$ Collected from HIV Clinics that use a local register; for example, blood sugar and cholesterol levels.

90.3\%-93.7\% depending on estimated linkage to care) were on ART. Additionally, 93.8\% of those on ART were virally suppressed (latest viral load $<50 \mathrm{HIV}-1$ RNA copies / $\mathrm{mL}$ ). Thus, by current estimation, $81 \%$ of all PLWH in
Finland are currently virally suppressed, and Finland has achieved the UNAIDS 90-90-90 target for 2020.

Comparison of the treatment results of the HIV Clinics shows that although the number of people who are treated 
Table 2 Characteristics of current (1984-2019) Finnish HIV Quality of Care Register population

\begin{tabular}{|c|c|c|}
\hline Information & n & $\%$ \\
\hline Population & 4218 & \\
\hline Valid PIC* & 3797 & 90.0 \\
\hline Women & 1192 & 28.3 \\
\hline Age at diagnosis & $\begin{array}{l}\text { Mean } 36.7 \\
\text { years }\end{array}$ & $\begin{array}{l}\text { Std } 12.3 \\
\text { years }\end{array}$ \\
\hline $\begin{array}{l}\text { CD4 +cell count at } \\
\text { diagnosis available }\end{array}$ & 1998 & 47.4 \\
\hline 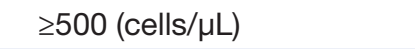 & 613 & $30.7 \dagger$ \\
\hline 350-499 (cells/ $\mu \mathrm{L})$ & 403 & $20.2 \dagger$ \\
\hline 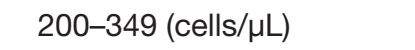 & 403 & $20.2 \dagger$ \\
\hline 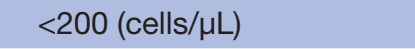 & 579 & $29.0 \dagger$ \\
\hline Diagnosed AIDS & 865 & 20.5 \\
\hline Deceased & 718 & 17.0 \\
\hline In follow-up at end of 2019 & 2763 & 65.5 \\
\hline \multicolumn{3}{|c|}{ Mode of transmission } \\
\hline Heterosexual & 1921 & 45.5 \\
\hline MSM§ & 1344 & 31.9 \\
\hline IDUף & 442 & 10.5 \\
\hline
\end{tabular}

$\begin{array}{lcc}\text { Vertical transmission } & 40^{* \star} & 0.95^{\star *} \\ \text { Other/unknown } & 471 & 11.2\end{array}$

\begin{tabular}{lrr}
$\begin{array}{lr}\text { Country of birth } \\
\text { Finland }\end{array}$ & 2561 & 60.7 \\
\hline Other & 1538 & 36.5 \\
\hline Unknown & 119 & 2.8 \\
\hline
\end{tabular}

\begin{tabular}{lrr}
$\begin{array}{lr}\text { Hepatitis } \mathrm{C} \text { antibodies } \\
\text { Positive }\end{array}$ & 380 & 9.0 \\
Negative & 2261 & 53.6 \\
\hline Unknown & 1577 & 37.4 \\
\hline
\end{tabular}

$\begin{array}{lll}\text { Hepatitis B S-antigen } & & \\ \text { Positive } & 91 & 2.2\end{array}$

\begin{tabular}{lll} 
Negative & 2546 & 60.4 \\
\hline Unknown & 1581 & 37.5
\end{tabular}

Continued
Table 2 Continued

\begin{tabular}{lll}
\hline Information & $\mathbf{n}$ & $\%$ \\
\hline
\end{tabular}

*Personal identity code. Invalidity usually due to recent immigration.

†lf measured in Finland 0-90 days after date of HIV diagnosis. Percentages reported as proportions of those with the cell count available $(\mathrm{n}=1998)$.

$\ddagger$ Alive and living in Finland with HIV viral level measured in 2019. §Men who have sex with men.

IIntravenous drug use.

${ }^{*}$ Of these, only three transmissions $(0.07 \%$ of the population) occurred in Finland.

IDU, Intravenous drug use; MSM, Men who have sex with men; PIC, personal identity code.

for HIV in each of the HIV Clinics ranges from under 10 to over 1600 , there are no significant differences in the proportion of those who are virally suppressed (figure 2). ${ }^{9}$

Of those with a CD4+ cell count measured within 90 days of HIV diagnosis $(\mathrm{n}=1998), 56.3 \%$ were diagnosed late (CD4+ cell count below 350 cells/ $\mu \mathrm{L}$ or AIDS diagnosed within 3 months of HIV diagnosis) and $37.0 \%$ were diagnosed very late $(\mathrm{CD} 4+$ cell count below 200 cells $/ \mu \mathrm{L}$ or AIDS diagnosed within 3 months of HIV diagnosis). In the national FINHIV data, HIV was diagnosed at a later stage than in a previous study in the Helsinki University Hospital population from 1985 to $2005 .{ }^{10}$ Over the last 20 years, there has been a slight rising trend in the proportions of late and very late diagnoses, with the proportions being $62 \%$ and $49 \%$ for those diagnosed in $2019 .{ }^{9}$

\section{STRENGTHS AND LIMITATIONS}

One of the strengths of the FINHIV data is nationwide coverage (including small clinics with few patients) from the start of the HIV epidemic in Finland. This enables evaluating the care of a whole national population cohort

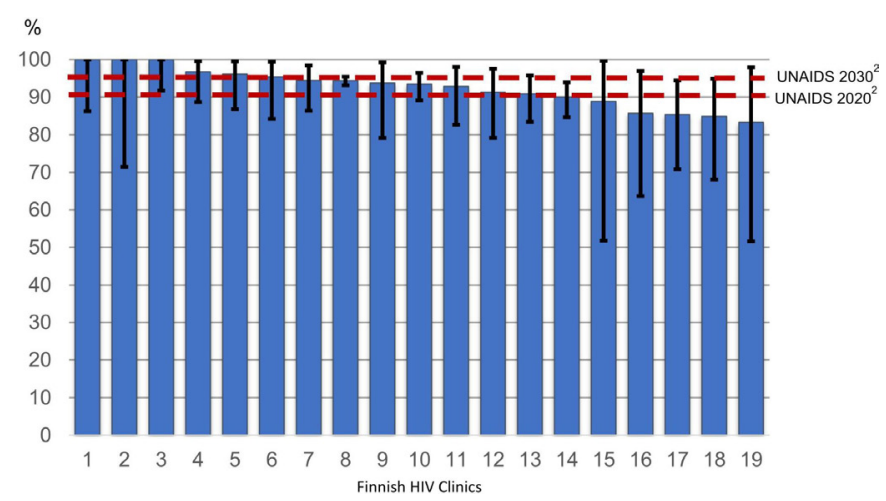

Figure 2 Virally suppressed ${ }^{1}$ of those on antiretroviral treatment in Finnish HIV Clinics in 2019. Figure reproduced from $^{9}$ with permission. The percentage of those virally suppressed is shown with $95 \%$ Cls. There are $21 \mathrm{HIV}$ clinics in Finland; the patients of the two smallest clinics ( $<5$ patients) are included in the results of the nearest larger clinic. ${ }^{1} \mathrm{HIV}-1$ RNA $<50$ copies/mL. ${ }^{2}$ The Joint United Nations Programme for HIV/AIDS (UNAIDS) target for years 2020 and 2030. 
and ensuring the equality of care between regions. The data in the register are collected routinely, either at regular follow-up visits (medical records/local register data) or by reporting to the NIDR, which is required by law. Yearly updates of the data will ensure that all new cases (current rate 150 new cases/year) will be included in the register and that missing information can be replaced with updated information.

PICs are used as identification in all healthcare contacts in the whole country as well as for collecting information to several national registers, which ensures accurate combining of data from different sources. National register linkage has been previously used to study motherto-child transmission of HIV and the management of delivery in women living with HIV in Finland, ${ }^{11} 12$ and further combinations will be used to examine factors related to the treatment of HIV infection (late diagnosis and retention to care) and other aspects of the health and welfare (eg, sexual health or cardiovascular risks) of the PLWH in Finland. Additionally, comparison of study results with the neighbouring countries of Sweden and Denmark is possible since they use similar national registers. ${ }^{13-16}$

Limitations of the register as a data source include the relatively small number of HIV diagnoses in Finland compared with many other countries. The total number of cases also includes a margin of error caused by the incomplete emigration data and the cases with invalid PICs. The majority of these cases were born in countries other than Finland (70\%, and for an additional 27\%, the country of birth is unknown). A few of them may still be duplicates that we could not reliably identify due to erroneous information in either entry, so the total number of diagnosed HIV cases in Finland is most likely slightly less than the 4218 included in the FINHIV. Based on our analysis of the available data, we presume, however, that most of the individuals registered under invalid PICs either stayed for only a short period of time and have already left the country or have recently immigrated and have yet to receive a valid PIC. In future updates of the register, methods for collecting additional data on emigration will be considered.

Additionally, the amount of missing data varies between variables; age at the time of HIV diagnosis is known for $100 \%$ and country of birth for $97 \%$ of the cases, while CD4+ cell count within 3 months of HIV diagnosis is missing from the earlier years and available for only $47 \%$ of the cases.

The ECDC HIV Modelling Tool does not take migration into account, which has been argued to make the estimate on the number of people living with undiagnosed HIV unreliable. ${ }^{17}$ In the current FINHIV population, $36.5 \%$ of those diagnosed are born in countries other than Finland with a growing proportion diagnosed before immigration, which affects the reliability of the estimated proportion of people who know of their HIV diagnosis.

\section{COLLABORATION}

The register is maintained in the THL. Access is restricted due to the nature of the data and use in research governed by law. ${ }^{18}$ For collaboration inquiries, contact Henrikki Brummer-Korvenkontio at THL (henrikki.brummer@ thl.fi). Anonymised data for scientific research can be requested from Data Permit Authority Findata that works in conjunction with THL (https://www.findata.fi/en/ services/data-requests/). Combining data from different registers for research purposes is possible. The compiled data are given in anonymised form to ensure that identifying individuals from the data is not possible.

Acknowledgements The authors would like to thank Antti Malmivaara (professor, visiting scholar at $\mathrm{THL}$ ) for his contribution to the initial concept of this cohort profile.

Contributors All authors took part in planning and organising the collection and analysis of the data. SI, HB-K and KL provided administrative support. OL was primarily in charge of the data transfer. J0, MM and $\mathrm{KL}$ conducted analyses of the data. PK, HB-K, MM, KL, IA and JO took part in interpretation of the data. PK conceptualised the manuscript based partly on a discussion with A. Malmivaara. MM wrote the draft for the manuscript with significant contributions from PK and IA. All authors critically revised and approved the draft. PK is the guarantor for the article.

Funding The authors have not declared a specific grant for this research from any funding agency in the public, commercial or not-for-profit sectors.

Competing interests Outside of the present work, PK and IA have received research grants from Gilead Nordic Fellowship Programme and report receiving personal fees (for lectures, travel expenses and Advisory Board participation) from Gilead, GSK and Merck.

Patient and public involvement Patients and/or the public were involved in the design, or conduct, or reporting, or dissemination plans of this research. Refer to the Methods section for further details.

\section{Patient consent for publication Not applicable.}

Ethics approval This study involves human participants and was approved by the Finnish Institute for Health and Welfare (THL) (THL/1572/6.02.00/2019). According to Finnish legislation, the use of retrospective register data for the kind of statistical analysis displayed in this article does not require informed consent.

Provenance and peer review Not commissioned; externally peer reviewed.

Data availability statement Data may be obtained from a third party and are not publicly available. Access to the data used in this study is restricted due to ethical reasons. For collaboration inquiries, contact Henrikki Brummer-Korvenkontio at THL (henrikki.brummer@thl.fi). Anonymised data for scientific research can be requested from Data Permit Authority Findata that works in conjunction with THL (https://www.findata.fi/en/services/data-requests/).

Open access This is an open access article distributed in accordance with the Creative Commons Attribution Non Commercial (CC BY-NC 4.0) license, which permits others to distribute, remix, adapt, build upon this work non-commercially, and license their derivative works on different terms, provided the original work is properly cited, appropriate credit is given, any changes made indicated, and the use is non-commercial. See: http://creativecommons.org/licenses/by-nc/4.0/.

ORCID iD

Mikaela Mutru http://orcid.org/0000-0002-7511-6812

\section{REFERENCES}

1 WHO. 90-90-90. An ambitious treatment target to help end the AIDS epidemic, 2014. Available: https://www.unaids.org/en/resources/ documents/2017/90-90-90 [Accessed 06 Jul 2020].

2 UNAIDS. Understanding fast-track. accelerating action to end the AIDS epidemic by 2030, 2015. Available: https://www.unaids.org/ sites/default/files/media_asset/201506_JC2743_Understanding_ FastTrack_en.pdf [Accessed 11 Feb 2021]. 
3 UNAIDS. Ending AIDS. progress towards the 90-90-90 targets, 2017. Available: https://www.unaids.org/en/resources/documents/2017/ 20170720_Global_AIDS_update_2017 [Accessed 27 Jan 2021].

4 Jonsson PM, Pikkujämsä S, Heiliö P. Kansalliset laaturekisterit sosiaali- ja terveydenhuollossa - Toimintamalli, organisointi ja rahoitus. Finnish Institute for Health and Welfare (THL). Raportti 16/2019, ISBN978-952-343-420-2, 2019. Available: https://www. julkari.fi/handle/10024/138834 [Accessed 28 Feb 2020].

5 Communicable diseases decree (786/1986) (1227/2016). Available: https://finlex.fi/fi/laki/smur/2016/20161227

6 Official Statistics of Finland (OSF). Quality description, migration 2019, 2020. Available: http://www.stat.fi/til/muut//2019/02/muutl_ 201902 2020-12-21 laa 001 en.html [Accessed 15 Mar 2021].

7 European Centre for Disease Prevention and Control. ECDC HIV Modelling Tool [software application]. Version 1.3.0, 2017. Available: https://ecdc.europa.eu/en/publications-data/hivmodelling-tool

8 van Sighem A, Nakagawa F, De Angelis D, et al. Estimating HIV incidence, time to diagnosis, and the undiagnosed HIV epidemic using routine surveillance data. Epidemiology 2015;26:653-60.

9 Finnish Institute for Health and Welfare (THL). Kivelä P for working group for HIV quality of care register pilot. Hiv-laaturekisteripilotin loppuraportti, 2020. Available: https://thl.fi/documents/2616650/ 4353715/Hiv-rekisteripilotti_loppuraportti.pdf
10 Kivelä PS, Krol A, Salminen MO, et al. Determinants of late HIV diagnosis among different transmission groups in Finland from 1985 to 2005. HIV Med 2010;11:360-7.

11 Aho I, Kivelä P, Kaijomaa M, et al. Comprehensive nationwide analysis of mother-to-child HIV transmission in Finland from 1983 to 2013. Epidemiol Infect 2018;146:1301-7.

12 Aho I, Kaijomaa M, Kivelä P, et al. Most women living with HIV can deliver vaginally-National data from Finland 1993-2013. PLoS One 2018;13:e0194370.

13 Obel N, Engsig FN, Rasmussen LD, et al. Cohort profile: the Danish HIV cohort study. Int J Epidemiol 2009;38:1202-6.

14 Helleberg M, Häggblom A, Sönnerborg A, et al. Hiv care in the Swedish-Danish HIV cohort 1995-2010, closing the gaps. PLoS One 2013;8:e72257

15 Omland LH, Ahlström MG, Obel N. Cohort profile update: the Danish HIV cohort study (DHCS). Int J Epidemiol 2014;43:1769-1769e.

16 Marrone G, Mellgren Åsa, Eriksson LE, et al. High concordance between self-reported adherence, treatment outcome and satisfaction with care using a Nine-Item health questionnaire in InfCareHIV. PLoS One 2016;11:e0156916.

17 Andersson E, Nakagawa F, van Sighem A, et al. Challenges in modelling the proportion of undiagnosed HIV infections in Sweden. Euro Surveill 2019;24.

18 Act on the secondary use of health and social data (552/2019). Available: https://finlex.fi/fi/laki/smur/2019/20190552 